\title{
Blood glucose test strips: options to reduce usage
}

\author{
Tara Gomes MHSc, David N. Juurlink MD PhD, Baiju R. Shah MD PhD, J. Michael Paterson MSc, \\ Muhammad M. Mamdani PharmD MA MPH
}

Previously published at www.cmaj.ca

$\infty \quad$ See related research article by Cameron and colleagues, page 28

\section{ABSTRACT}

Background: Recent evidence suggests that, despite widespread use, self-monitoring of blood glucose levels has little clinical benefit in many patients with diabetes. The impact of more focused public-payer policies for the use of blood glucose test strips may be substantial.

Methods: We conducted a cross-sectional analysis of annual prescription claims for test strips between 1997 and 2008 for patients in Ontario aged 65 and older with diabetes. Patients were stratified into 1 of 4 hierarchical groups according to the most intensive glucose-lowering treatment received during each calendar year. Test strip use was calculated annually for each group over the study period, and the effects of 5 hypothetical policy scenarios of more selective test strip use were assessed.

Results: Test strip use increased by almost 250\% from 1997 to 2008 , with $52.6 \%$ ( $n=263513$ ) of included patients receiving a prescription during 2008. Almost half of these patients were at low risk for drug-induced hypoglycemia. In 2008, over 117 million test strips were dispensed in Ontario; however, more focused policy scenarios could have reduced this number by between 9.5 million and 74.5 million test strips.

Interpretation: Many people who self-monitor their blood glucose are at relatively low risk for drug-induced hypoglycemia. The economic benefits associated with more selective testing could be redirected to more effective interventions for patients with diabetes.

$\mathrm{T}$ he Canadian Diabetes Association and the American Diabetes Association recommend self-monitoring of blood glucose for patients with diabetes to monitor their glycemic control..$^{1,2}$ Although guidelines exist about the use of blood glucose test strips for patients taking insulin, the effectiveness and optimal frequency of self-monitoring of blood glucose in patients not taking insulin is controversial. ${ }^{3,4}$ Several lines of evidence suggest increased discomfort, inconvenience and worsening of depression scores with regular selfmonitoring, along with a lack of clinically relevant improvement in diabetes-related outcomes in patients who self-test and are not taking insulin..$^{5-12}$ Indeed, the Canadian Agency for
Drugs and Technologies in Health has recommended against the routine use of blood glucose test strips for most adults with type 2 diabetes using oral hypoglycemic agents. ${ }^{1,13}$

The impact of translating this evidence to more focused policy decisions for blood glucose testing is unknown but may be considerable. In Ontario in 2007/08, blood glucose test strips represented the third largest expenditure by the Ontario Public Drug Programs, after atorvastatin and amlodipine besylate, accounting for over $\$ 100$ million, or $3.3 \%$ of total drug expenditures..$^{14}$ We sought to characterize the patterns of test strip use among patients aged 65 and older according to the type of diabetes therapy received and to estimate the impact of several scenarios related to testing frequency on the use of test strips.

\section{Methods}

\section{Study design and data sources}

We conducted a cross-sectional time-series analysis of annual prescription claims for blood glucose test strips reimbursed by the Ontario Public Drug Program over a 12-year period (January 1997 to December 2008) for people in Ontario aged 65 and older. The Ontario Drug Benefit database and the Ontario Diabetes Database were used to identify reimbursement claims for blood glucose test strips and to determine diabetes status, respectively. These databases have been described previously. ${ }^{15-17}$

The study was approved by the Research Ethics Board of Sunnybrook Health Sciences Centre, Toronto.

\section{Inclusion criteria}

We included patients aged 65 and older who filled at least 1 prescription for blood glucose test strips between 1997 and

From the Department of Medicine (Juurlink, Shah), Sunnybrook Health Sciences Centre, Toronto, Ont.; St. Michael's Hospital (Mamdani) Toronto, Ont.; the Departments of Medicine (Mamdani, Juurlink, Shah), Pediatrics (Juurlink), and Health Policy, Management, and Evaluation (Mamdani, Juurlink, Shah), University of Toronto, Toronto, Ont.; the Institute for Clinical Evaluative Sciences (Gomes, Mamdani, Juurlink, Paterson, Shah), Toronto, Ont.; the Department of Family Medicine (Paterson), McMaster University, Hamilton, Ont.; and the Centre for Evaluation of Medicines (Paterson), St. Joseph's Healthcare; Hamilton, Ont.

CMAJ 2009. DOI:10.1503/cmaj.091017 
2008. Patients were assigned to yearly cohorts if they filled at least 1 test strip prescription during the calendar year. They were then stratified into 1 of 4 hierarchical and mutually exclusive groups each year according to the most intensive diabetes therapy received during that year using drug claims from the Ontario Drug Benefit database (Table 1).

\section{Statistical analysis}

For each year, we determined the number of prescriptions for test strips and the total number of test strips dispensed to patients in each diabetes therapy group. To calculate the rates of test strip use within each diabetes therapy group, we used as the denominator all patients aged 65 years or older who

Table 1: The use of blood glucose test strips in Ontario in 2008 among patients with diabetes aged 65 and older

\begin{tabular}{|c|c|c|c|c|c|}
\hline \multirow[b]{2}{*}{ Diabetes therapy received } & \multicolumn{5}{|c|}{ No. (column \%)* } \\
\hline & $\begin{array}{l}\text { Patients } \\
\text { prescribed test } \\
\text { strips (row \%) }\end{array}$ & $\begin{array}{l}\text { Claims for test } \\
\text { strips }\end{array}$ & $\begin{array}{l}\text { Test strip claims } \\
\text { per patient, } \\
\text { mean (SD) }\end{array}$ & $\begin{array}{l}\text { Test strips } \\
\text { dispensed }\end{array}$ & $\begin{array}{l}\text { Test strips per } \\
\text { patient per day, } \\
\text { mean (SD) }\end{array}$ \\
\hline $\begin{array}{l}\text { Group 1: Insulint } \\
n=65792\end{array}$ & $56772(86.3)$ & 311415 (33.8) & $5.49(3.82)$ & 43121314 (36.7) & $2.08(1.71)$ \\
\hline $\begin{array}{l}\text { Group 2: Hypoglycemia- } \\
\text { inducing oral glucose-lowering } \\
\text { drugsf, } \\
n=134758\end{array}$ & $83059(61.6)$ & $283915(30.8)$ & $3.42(2.80)$ & $35283961(30.0)$ & $1.16(1.01)$ \\
\hline $\begin{array}{l}\text { Group 3: Nonhypoglycemia- } \\
\text { inducing oral glucose-lowering } \\
\text { drugs§ } \\
n=130807\end{array}$ & $75134(57.4)$ & $213252(23.1)$ & $2.84(2.35)$ & $25817898(22.0)$ & $0.94(1.19)$ \\
\hline $\begin{array}{l}\text { Group 4: No glucose-lowering } \\
\text { drug therapy** } \\
n=169449\end{array}$ & $48548(28.7)$ & $113445(12.3)$ & $2.34(2.09)$ & 13380519 (11.4) & $0.75(0.74)$ \\
\hline All diabetes therapy groups & 263513 & 922027 & $3.50(3.04)$ & 117603692 & $1.22(1.30)$ \\
\hline
\end{tabular}

Note: SD = standard deviation

*Unless otherwise indicated.

tAt least 1 prescription for insulin, regardless of other diabetes drug therapy

¥At least 1 prescription for an oral glucose-lowering drug that may induce hypoglycemia (repaglinide or sulfonylureas) but not insulin.

$\S$ At least 1 prescription for an oral glucose-lowering drug not generally associated with hypoglycemia (metformin, thiazolidinediones or acarbose) but not insulin or a hypoglycemia-inducing oral glucose-lowering drug.

**No prescription for an oral glucose-lowering drug or insulin.

Table 2: Reduction in the use of glucose test strips associated with 5 scenarios related to testing frequency

\begin{tabular}{|c|c|c|c|c|c|c|}
\hline \multirow[b]{2}{*}{ Scenario } & \multicolumn{5}{|c|}{ No. of test strips by group } & \multirow{2}{*}{$\begin{array}{l}\text { Total } \\
\text { reduction, } \\
\text { no. of strip }\end{array}$} \\
\hline & $\begin{array}{c}1 \\
n=56722\end{array}$ & $n=83059$ & $\begin{array}{c}3 \\
n=75134\end{array}$ & $\begin{aligned} & 4 \\
n= & 48548\end{aligned}$ & $\begin{array}{c}\text { All } \\
n=263513\end{array}$ & \\
\hline Calendar year 2008 & 43121314 & 35283961 & 25817898 & 13380519 & 117603692 & NA \\
\hline $\begin{array}{l}\text { Unlimited use in group 1; no use of blood } \\
\text { glucose test strips in groups } 2,3 \text { and } 4\end{array}$ & 43121314 & 0 & 0 & 0 & 43121314 & 74482378 \\
\hline $\begin{array}{l}\text { Unlimited use in group 1; a maximum of } 100 \\
\text { strips per person per year in groups } 2 \text { and } 3 ; \\
\text { no use of blood glucose test strips in group } 4\end{array}$ & 43121314 & 8297060 & 7501897 & 0 & 58920271 & 58683421 \\
\hline $\begin{array}{l}\text { Unlimited use in groups } 1 \text { and } 2 \text {; a maximum } \\
\text { of } 100 \text { strips per person per year in groups } 3 \\
\text { and } 4\end{array}$ & 43121314 & 35283961 & 7501897 & 4837027 & 90744199 & 26859493 \\
\hline $\begin{array}{l}\text { Unlimited use in groups } 1 \text { and } 2 \text {; a maximum } \\
\text { of } 200 \text { strips per person per year in groups } 3 \\
\text { and } 4\end{array}$ & 43121314 & 35283961 & 12738704 & 7604377 & 98748356 & 18855336 \\
\hline $\begin{array}{l}\text { Unlimited use in groups } 1 \text { and } 2 \text {; a maximum } \\
\text { of } 400 \text { strips per person per year in groups } 3 \\
\text { and } 4\end{array}$ & 43121314 & 35283961 & 19130621 & 10539705 & 108075601 & 9528091 \\
\hline
\end{tabular}

Note: group 1 = insulin; group 2 = hypoglycemia-inducing oral glucose-lowering drug; group 3 = nonhypoglycemia-inducing oral glucose-lowering; group 4 = no glucose-lowering drug therapy. NA = not applicable. 
met the criteria outlined in Table 1. For patients receiving no glucose-lowering drug therapy, the denominator was determined from the Ontario Diabetes Database after excluding patients receiving diabetes therapy. ${ }^{15}$

Despite evidence that self-monitoring of blood glucose does not improve glycemic control in patients not requiring insulin, self-monitoring may promote patient engagement and awareness of diabetes. ${ }^{18}$ Furthermore, patients who receive oral hypoglycemic agents may find periodic monitoring useful to detect hyperglycemia or hypoglycemia. We modelled the implications of 5 different self-monitoring testing scenarios (Table 2) within our 4 diabetes therapy groups. The first 2 scenarios were guided by the recent Canadian Agency for Drugs and Technologies in Health recommendations, ${ }^{13}$ allowing limited or no self-monitoring of blood glucose testing for patients taking oral glucose-lowering drugs. In both scenarios, we imposed no limit on the number of strips dispensed to patients taking insulin. The last 3 scenarios were directed at test strip use among patients at low risk for drug-induced hypoglycemia. The thresholds (100, 200 or 400 strips per year) correspond to approximate testing frequencies of twice weekly, every second day and daily, respectively. The potential impact on the use of blood glucose test strips associated with each of these scenarios was estimated for calendar year 2008 .

\section{Results}

During the study period, the use of blood glucose test strips among patients aged 65 years or older increased by almost $250 \%$, from 76320 people in 1997 to 263513 in 2008. About $53 \%$ of the included patients had received diabetes test strips by 2008 . The total number of blood glucose test strips dispensed increased almost 5-fold, from 24.9 million strips in 1997 to 117.6 million strips in 2008. These trends in increasing use were observed in all diabetes therapy groups, with the prevalence of the use of blood glucose test strips more than doubling among patients not taking glucose-lowering drugs and exceeding $80 \%$ among patients using insulin.

On average, patients using insulin were dispensed more than 5 prescriptions for test strips in 2008 (mean 5.49, standard deviation 3.82), reflecting the use of more than 2 test strips per day on average (Table 1). Although these patients received almost twice as many test strips on average than patients in any other group, patients not receiving insulin accounted for $63.3 \%$ of all blood glucose test strips used in 2008 .

Under the 5 scenarios considered, the use of test strips would be reduced substantially among older patients (Table 2). Even with the most conservative approach, in which patients at low risk of drug-induced hypoglycemia tested daily and with no other restrictions, test strip use could have been reduced by 9.5 million test strips or roughly $8.1 \%$ of total use. Under the most stringent criteria, the reduction would be almost 75 million strips (63\% of total use).

\section{Interpretation}

Over the last 12 years in Ontario, the self-monitoring of blood glucose among older patients has increased by more than
$250 \%$, with use increasing among all diabetes patient groups, including those at low risk of drug-induced hypoglycemia. Overall, $30 \%$ of patients who did not use drug therapy to control their diabetes and $60 \%$ of patients taking oral glucoselowering drugs not known to cause hypoglycemia were dispensed blood glucose test strips, despite evidence of no clear clinical benefit and some suggestion of harm. This may reflect an increased focus on blood glucose monitoring as part of routine care or increased licensing, formulary approval and marketing of new blood glucose test strips.

In light of the overall costs and questionable benefits for many patients, more focused policy decisions about the use of test strips have been proposed in several jurisdictions. ${ }^{13,19} \mathrm{We}$ estimate that under some of these policies, test strip use among older patients could have been reduced by between 9.5 million and 74.5 million in 2008. Without such policies, over the next 5 years the growing costs of self-monitoring will undoubtedly exceed $\$ 1$ billion in Canada. The cost implications of such policies are therefore substantial.

Although our estimates are derived from hypothetical scenarios, they illustrate the potential impact of self-testing in a manner more consistent with the available evidence. Substantial changes in use and costs could be realized without altering test strip use among patients taking insulin or oral agents that can cause hypoglycemia. ${ }^{20}$ It should be emphasized that in all but 1 of the scenarios described, the reported changes would result from a lowering of potentially unnecessary use of blood glucose test strips, while still permitting blood glucose monitoring by all patients receiving drug treatment. This would continue to engage patients in their own care and allow them to gather data that may aid clinical decision-making.

\section{Conclusion}

Even modest changes in the frequency of self-monitoring of blood glucose among selected patients with type 2 diabetes through focused policy decisions could lead to substantial reductions in test strip use. Any associated cost reductions could be used to improve diabetes care in ways that are better supported by evidence, without limiting reimbursement for blood glucose test strips for patients at risk of drug-induced hypoglycemia.

\section{This article has been peer reviewed.}

Competing interests: Tara Gomes was employed by the Ministry of Health and Long-Term Care from September 2007 to September 2008 and is currently employed by the Institute for Clinical Evaluative Sciences (ICES). J. Michael Paterson, David Juurlink, Baiju Shah and Muhammad Mamdani are scientists with ICES, which is funded by the Ontario Ministry of Health and Long-Term Care.

Contributors: All of the authors contributed to the conception and design of the study. Tara Gomes collected the data, and all of the authors contributed to the analysis and interpretation of the data. Tara Gomes drafted the article. All of the authors revised it critically for important intellectual content and approved the final version submitted for publication.

Acknowledgements: David Juurlink was supported by a New Investigator Award from the Canadian Institutes for Health Research. Baiju Shah is supported by the Canadian Institutes of Health Research, the Canadian Diabetes Association and the Banting and Best Diabetes Centre, University of Toronto. 
Funding: This study was supported by the Ontario Drug Policy Research Network, which is funded by the Ontario Drug Innovation Fund and the Institute for Clinical Evaluative Sciences, a nonprofit research corporation sponsored by the Ontario Ministry of Health and Long-Term Care.

The opinions, results and conclusions reported in this paper are those of the authors and are independent from the funding sources. No endorsement by the Institute for Clinical Evaluative Sciences or the Ontario Ministry of Health and Long-Term Care is intended or should be inferred.

\section{REFERENCES}

1. Canadian Diabetes Association Clinical Practice Guidelines Expert Committee Canadian Diabetes Association 2008 clinical practice guidelines for the prevention and management of diabetes in Canada. Can J Diabetes 2008;32:S1-201.

2. American Diabetes Association. Standards of medical care in diabetes - 2009 . Diabetes Care 2009;32(Suppl 1):S13-61.

3. National Prescribing Centre of the National Health Service. When and how should patients with diabetes mellitus test blood glucose? MeReC Bulletins 2002;13:1-4

4. Karter AJ. Role of self-monitoring of blood glucose in glycemic control. Endocr Pract 2006;12(Suppl 1):110-7.

5. Faas A, Schellevis FG, Van Eijk JT. The efficacy of self-monitoring of blood glucose in NIDDM subjects. A criteria-based literature review. Diabetes Care 1997;20:1482-6.

6. Davidson MB, Castellanos M, Kain D, et al. The effect of self-monitoring of blood glucose concentrations on glycated hemoglobin levels in diabetic patients not taking insulin: a blinded, randomized trial. Am J Med 2005;118:422-5.

7. Farmer A, Wade A, Goyder E, et al. Impact of self-monitoring of blood glucose in the management of patients with non-insulin treated diabetes: open parallel group randomised trial. $B M J$ 2007;335:132.

8. Guerci B, Drouin P, Grange V, et al. Self-monitoring of blood glucose significantly improves metabolic control in patients with type 2 diabetes mellitus: the Auto-Surveillance Intervention Active (ASIA) study. Diabetes Metab 2003;29: 587-94.

9. O'Kane MJ, Bunting B, Copeland M, et al. Efficacy of self monitoring of blood glucose in patients with newly diagnosed type 2 diabetes (ESMON study): randomised controlled trial. BMJ 2008;336:1174-7.

10. Kennedy L. Self-monitoring of blood glucose in type 2 diabetes: time for evidence of efficacy. Diabetes Care 2001;24:977-8

11. Canadian Optimal Medication Prescribing and Utilization Service. Systematic review of use of blood glucose test strips for the management of diabetes mellitus. Ottawa (ON): Canadian Agency for Drugs and Technologies in Health; 2009.
Available: www.cadth.ca/media/pdf/compus_Draft_BGTS_SR_report_of_clinical _outcome.pdf (accessed 2009 Oct. 20).

12. Davis WA, Bruce DG, Davis TM. Does self-monitoring of blood glucose improve outcome in type 2 diabetes? The Fremantle Diabetes Study. Diabetologia 2007;50:510-5.

13. Canadian Optimal Medication Prescribing and Utilization Service. Optimal therapy recommendations for the prescribing and use of blood glucose test strips. Ottawa (ON): Canadian Agency for Drugs and Technologies in Health; 2009. Available: www.cadth.ca/index.php/en/compus/compus-publications/publication 1874 (accessed 2009 Oct. 20).

14. Ontario Ministry of Health and Long-Term Care. 2007/08 interim report card for the Ontario Drug Benefit program. Ottawa (ON); 2009. Available: www.health .gov.on.ca/en/public/publications/ministry_reports/odb_report08/drug_rep08.aspx (accessed 2009 Oct. 20).

15. Hux JE, Ivis F, Flintoft V, et al. Diabetes in Ontario: determination of prevalence and incidence using a validated administrative data algorithm. Diabetes Care 2002;25:512-6.

16. Gomes T, Juurlink DN, Lipscombe LL, et al. Clinical and demographic characteristics of patients receiving different oral hypoglycemic agents. Pharmacoepidemiol Drug Saf 2009; 18:756-60.

17. Levy AR, O'Brien BJ, Sellors C, et al. Coding accuracy of administrative drug claims in the Ontario Drug Benefit database. Can J Clin Pharmacol 2003;10:67-71.

18. Canadian Optimal Medication Prescribing and Utilization Service. Current practice analysis of health care providers and patients on self-monitoring of blood glucose. Ottawa (ON): Canadian Agency for Drugs and Technologies in Health; 2009. Available: www.cadth.ca/media/pdf/compus_Current_Practice_Report_Vol-3-Issue-5.pdf (accessed 2009 Oct. 20)

19. Sanyal C, Graham SD, Cooke C, et al. The relationship between type of drug therapy and blood glucose self-monitoring test strips claimed by beneficiaries of the Seniors' Pharmacare Program in Nova Scotia, Canada. BMC Health Serv Res 2008;8:111.

20. Gomes T, Juurlink DN, Shah BR, et al. Blood glucose test strip costs and potential savings associated with reduced testing. ICES Investigative Report. Toronto (ON): Institute for Clinical Evaluative Sciences.

Correspondence to: Muhammad M. Mamdani, Applied Health Research Centre, Li Ka Shing Knowledge Institute of St. Michael's Hospital, 30 Bond St., Toronto ON M5B 1W8;

mamdanim@smh.toronto.on.ca

\section{ath $\begin{array}{ll}\text { Health } & \text { Santé } \\ \text { Canada } & \text { Canada }\end{array}$ \\ $\begin{array}{ll}\begin{array}{l}\text { Your health and } \\ \text { safety...our priority. }\end{array} & \begin{array}{l}\text { Votre santé et votre } \\ \text { sécurité... notre priorité. }\end{array}\end{array}$}

Canadian Adverse Reaction Newsletter Highlights from the January 2010 issue of Health Canada's Canadian Adverse Reaction Newsletter.

- Black cohosh products and liver toxicity: update

- Redesign of the Canada Vigilance Adverse Reaction Online Database

- $\quad$ Chronic, excessive use of denture adhesive creams: suspected association with neuropathy

- Quarterly summary of advisories

Visit the MedEffect ${ }^{\mathrm{TM}}$ Canada Web site at

www.healthcanada.gc.ca/medeffect to view or to subscribe for free to the Newsletter and other health products advisories.

Canadä

\section{* Santé $\begin{gathered}\text { Health } \\ \text { Canada }\end{gathered}$ \\ $\begin{aligned} & \text { Votre santé et votre } \\ & \text { sécurité... notre priorité. }\end{aligned}$
$\begin{aligned} & \text { Your health and } \\ & \text { safety....our priority }\end{aligned}$}

Bulletin canadien des effets indésirables Les grandes lignes du numéro de janvier 2010 du Bulletin canadien des effets indésirables de Santé Canada.

- Actée à grappes noires et toxicité du foie : mise à jour

- Base de données en ligne des effets indésirables de Canada Vigilance : restructurée

- Usage chronique et excessif de crèmes adhésives pour prothèses dentaires : lien soupçonné avec la neuropathie

- Sommaire trimestriel des avis

Visitez le site Web MedEffet ${ }^{\mathrm{MC}}$ Canada à www.santecanada.gc.ca/medeffet pour consulter ou vous abonner gratuitement au Bulletin et aux avis sur les produits de santé.

Canadă 